\title{
Empathic Listening as a Transferable Skill
}

\author{
ANTHONY GRITTEN [1] \\ Royal Academy of Music, UK
}

\begin{abstract}
This text responds to Deniz Peters' argument with three things: a broad context for empathic listening based on its value as a transferable skill; a comment on the relationship between musical empathy and "social empathy via music"; and a comment on the "indeterminacy" at the beginning of empathic listening.
\end{abstract}

Submitted 2014 August 21; accepted 2014 November 5.

KEYWORDS: empathy, listening, transferable skill

IN many ways empathy is a paradigm of transferable skill. However it might be defined in detail in terms of its properties, its development, its usage, and its significance, and, notwithstanding its fluctuating terminology and relation to similar phenomena (e.g. the nuanced distinctions between "empathy," "sympathy," and "contagion"), empathy seems to be a general human skill with functionality and use value across numerous domains and the potential to heal rifts and improve relationships between citizens. Empathy is said to have the ability to make a "potential contribution to human capital" (Hodges \& Klein, 2001, p. 439), and it is sufficiently broad in scope that Husserl made sure that his phenomenology afforded the subject "windows of empathy" onto the other (Husserl as cited in Smith, 2003, pp. 201 \& 233).

The literature on empathy, including the literature on empathy in music, is the nexus for a massive confluence of interdisciplinary themes and perspectives on empathy. These range from studies of medical interviewing techniques through psychoanalysis and conflict resolution to research into pedagogy and education. The history of the term and concept of empathy (Wispé, 1987) reveals its transferability, through various historical appropriations, displacements, and reinventions, from the psychology of aesthetic experience through interpersonal social interaction through clinical psychotherapy through to the recent joining up of empathy to the neural bases of musicking in the mirror neuron system (Molnar-Szakacs \& Overy, 2006; Overy \& Molnar-Szakacs, 2009). Empathy is one of those Ur-skills and intended learning outcomes that is quietly incorporated into numerous value systems, if not always also into the educational curricula that could be used to develop and nurture it to the best advantage, and it is often embedded and assumed at such a deep level of musical practice that it underpins the subject matter silently with little conscious notice paid to it (the hermeneutics of critical musical interpretation provides a good example of a practice with its deepest roots buried - and often hidden - in empathy). Empathy has even been described as, like taste and hearing, one of the body's senses (Haney, 1994, pp. 62 \& 64). As a transferable skill, empathy is one of a large constellation of cognate terms that denote the subject's interest in other subjects $q u a$ others and that denote the subject's desire for a reciprocal engagement with the other to mutual benefit: sympathy, intimacy, communicative musicality, inter-subjectivity, turn-taking, attunement, entrainment, understanding, sociality, respect, and love.

Deniz Peters' argument in "Musical Empathy, Emotional Co-Constitution, and the 'Musical Other"' (2015) passes to and fro between three main claims about musical empathy. The first claim is that empathy needs to be configured as an "imaginative" engagement, not with the performer or composer, but, following Jerrold Levinson, with a musical "persona" (p. 6). The second claim is that empathic listening needs to be configured in such a way that it incorporates the key bodily, "felt" aspects of musical experience, in which there is an interaction between "cross-modal sensations" and "a bodily hermeneutic" (p. 7); herein lies the primary rationale for empathic listening as a transferable skill-as the body's developmental adaptation to cross-modal neural events. The third claim is that we should distinguish between "musical empathy" and what Peters calls "social empathy via music" (in which music is effectively a mere cipher). These three claims are related by Peters to a conventional position on the musical expression of emotion (the ideology that this is the most important thing that music must do, perhaps even the only thing that is required of it), but this seems to me to narrow down the scope of his 
account of empathy to a contingent tale about the egological Western Classical tradition only and to reduce the scope of empathic listening's function as a transferable skill, so I shall leave it to one side in this essay.

In the next section I provide a brief account of how empathy develops as a transferable skill in order to unpack part of the context surrounding Peters' argument and to prepare the ground for two points of discussion. In the literature "empathic" and "empathetic" seem to be used interchangeably; I use the former.

\section{EMPATHIC LISTENING}

What is this transferable skill of empathy? With regard to Western Classical music specifically, what is meant by the praxis of "empathic listening"? And how does it develop best? These three questions can be considered together.

Beginning at a general level, empathy is usually defined as "the understanding of, sensitivity towards and ability to adequately respond to another's feelings" (Rabinowitch, 2012, p. 80) or sometimes as "derived sensitivity" (Haney, 1994, p. 57). Ignoring possible ambiguities in the way in which "understanding" and "sensitivity" are related (it is surely more productive to configure the former as a subset of the latter), definitions like this usefully tease apart empathy into various components, here three in number: "understanding," "sensitivity," and practical "ability." A complementary approach to shared musical experience proposes a similar set of three components: "(1) joint sense-making, enacted via temporally extended patterns of (2) skilful engagement with music that are (3) synchronically and diachronically scaffolded by the surrounding environment" (Krueger 2013, p. 177).

More fundamentally, there is a basic movement of consciousness in empathy whereby the subject's attention is divided and divides: as Simon Baron-Cohen puts it (2011, p. 10), "Empathy occurs when we suspend our single-minded focus of attention, and instead adopt a double-minded focus of attention." This Janus-faced division of attention-sometimes described in the ensemble performance literature as a "decentering" of the self (Seddon 2005) - has cognitive and affective components: respectively, turn-taking or perspective-taking, and an emotional response. One psychoanalyst has defined empathy as follows, highlighting the delicate balancing act of empathy between intervention and facilitation:

Viewed from an epistemological perspective, empathy in psychoanalytic practice is described as that aspect of a specialized attentional stance that opens channels of interaction facilitating the formation of a trusting bond and enabling one to gain access to the emotional qualities of another's experience. (Aragno, 2008, p. 713)

Within the domain of music, and more specifically the experience of listening to music, research reveals that the degree of interpersonal success of an experience, its "empathic accuracy," turns on various psychological and interpersonal factors. These factors include individual character, temperament, attitude, and the basic set of values and worldview that ground and motivate the listener in her evolving (inter-) subjectivity.

It is frequently acknowledged that prolonged, repeated, and attentive listening affords the development of certain personal qualities in the listener, qualities that have wider usage than in just the kinds of musical experiences from which they are derived. Acknowledgments can be read across a whole variety of discourses, from the loosely framed work of pedagogy, criticism, and journalism through to the fine-grained inspections of empirical psychology. But what are these transferable skills that collectively form a constellation around empathy? A list of them includes the following: a willingness to extemporize possibilities other than those of one's own devising; self-criticism; patience; a non-possessive attitude towards musical property (to an extent, excessive claims of aesthetic ownership are prevented structurally by what Peters calls "co-constitution," where the labor of listening is distributed between the listener and the "musical other"); and comfort with relationships, decisions, and judgments based on affinities rather than exactitudes. As we know, musical engagement involves "the plaiting or braiding of strands to create a single chord, which has discernible, constituent filaments, but whose whole is clearly greater than the sum of its parts" (Boddington \& Bannerman, 2004, p. 79). It is a matter of improvisatory action and emergence, and is really more than the mere physiological interaction between listener and music. It is also a vicarious confession by the listener, both jointly with the musical other and individually to that musical other, during which are made public beliefs, views, and judgments that probably otherwise remain personal, concealed, 
and unarticulated. In this respect, it requires a commitment and intimacy (Krueger, 2013, p. 177) - a balance between exposure and regulation. Peters describes it as "doubly active," a matter of the intertwining of "tactile and kinaesthetic knowledge" with imaginative interpretation (p. 7); others, following Alf Gabrielsson, might phrase it in terms of the demand to maintain an ongoing healthy balance between "recognized" and "felt" emotions in musical listening - that the boundary between the two needs to be maintained (e.g. Egermann \& McAdams, 2013). The broader point here is that it is precisely the "intimacy" and "risk" of empathic listening that afford the development of transferable skills, those skills that have benefits elsewhere in the subject's life, that contribute to the accumulation of social capital, and that arguably serve a deep adaptive function in being grounded in the auditory system ahead of the other senses.

Empathy does not usually benefit from loud negotiation and invasive intervention: it seems to work best - most creatively — when silent, slowly evolving and unwritten. Rather, like love, empathy seems to be weaker when it is forced into being fully articulated. Determined empathy risks being decreased empathy, and forced empathy risks not being empathy at all-indeed, we could suggest in passing that forced empathic listening is on the verge of morphing into structural listening. Thus, there are some key pragmatics to empathic listening. The listener tends to ease her way into an empathic relationship with a musical persona, extemporizing her way towards feelings, perceptions, and judgments of empathy. She tends to avoid articulating anything too explicitly, not because doing so is vulgar or anti-aesthetic, but because doing so is unnecessary behind the more pressing issues of creating and maintaining a shared musical experience. Another way of putting this is to say that empathic listening has to be developed, rather than implemented, accumulated rather than bought. It is not a plan for actioning or a problem to be solved, but a practice that emerges - or does not — under its own head of steam.

Thus, given the mutual dependence of the listener on the musical other (and vice versa, as Peters points out), their reciprocal musical engagement requires willingness and self-motivation, especially given that the distribution of labor forces both the listener and the musical persona to cede a degree of artistic control (though not necessarily musical input) into some aspects of the engagement, this being the flipside of gaining primary control for other aspects of the engagement. This is reflective judgment within the "coconstitution" of the musical persona: a responsive, flexible, sensitive, loose, and open attention to the particular changes and transformations over time of musical events, gestures, ideas, and proposals that are articulated performatively more than verbally, with an emphasis on local contexts, the body language of musical exchanges, rehearsals, and so on. As Peters says, "Musical empathy is empathy with a protean agency, an agency whose sometimes mundane and sometimes bizarre body and psyche emerges, profoundly co-constituted, from ours" (2015, p. 10). What the listener seeks, then, is a type of thinking characterized by a lightness of touch and graceful receptivity to sensations and ideas. Such a thought operates with a different type of precision to cognition. It also feeds on a psycho-social trait that is found in many different types of musicians, namely sensitivity (Kemp, 1996, pp. 68-84).

Empathy is helpful, for it goes beyond morals and wisdom, beyond the belief (or otherwise) in the composer's personal character and the performer's individual abilities (Peters demolishes both of these ideas quickly at the outset of his article), and beyond the current listening experience to reach further outwards into the deeper evolving totality of the listener's life. It is essentially a relation of resonance, a heuristic device that affords the listener a way of dealing with complexities in her relation to the musical persona that otherwise might require impractical rationalization; it is a way of imaginative thinking "as if" (Cameron, 2011, p. 10). It can thus be useful in time-constrained situations, since it affords decisions, judgments, and actions based on partial information, as is the case in much listening, as well as in new musical situations (e.g. hearing a piece for the first time), in which the transferability of empathic listening skill affords a means of quickly apprehending the shape and dynamics of the new domain. The distribution of labor in, say, a string quartet involves a transfer of resources from the listener both to the four live performers and to the musical persona, all of whom, by virtue of that mutual transfer, possess an implicit power, not only over their individual parts of the listening experience, but over the event as a whole. Empathy requires a certain amount of self-abnegation on the part of the listener, and this can be hard, resisting the inherited weight of domineering ideologies of listening. Thus, the listener (and indeed the performer) is challenged to develop the ability to know who, what, when, and how to empathize, and a working sensitivity to the claims and contexts of multiple information sets - and how to recognize and individuate a "pluralistically constituted" (Peters, 2015, p. 9) musical persona when it emerges. Empathy in this sense is a cross-domain transferable skill for learning and adaptation, and pragmatism suggests that "We learn through attending to contexts, vocabulary develops through close attention to objects, and we 
can only understand others if we can to some extent share their contexts" (Murdoch, 1970, p. 31). Such "sharing" playing a central part in empathic listening.

This means that empathic listening, which involves, inter alia, the ability to live with and be productive after - and sometimes despite - the consequences of distributing the labor of listening between listener, performer, musical other, and persona, emerges through musical practice and over time. It is a creative skill that probably not every listener can develop, for it is "the result of very personal, preconditional, and eccentric ideas working illogically below the level of consciousness to reshape conscious thinking" (Skura, 1980, p. 133). This proposal has ramifications for the sense of subjectivity that the empathic listener might develop. First and foremost, subjectivity is emergent rather than predetermined and in a very tangible sense multiply authored, and thus potentially also multiply owned and distributed. Hence the importance of the listener trusting, not only that there is something significant happening over the course of the listening experience itself, but also trusting that after the musical experience (note the tense) there will have been something significant and empathic from which human value can be extrapolated, as well as the importance of relying on her bodily engagement with the music as a source of interpretative energy - the listener's body being, as Peters insightfully notes, the site "from which we embark on a more elaborate bodily interpretation and empathetic inquiry" $(2015$, p. 8).

\section{TYPES OF EMPATHY}

In this section, I comment briefly on one issue that seems to cut across Peters' argument about the expression of emotion, and that represents what I read as Peters' take on the issue of whether and how empathic listening should be considered to be a transferable skill. This is the relation between musical empathy and social empathy.

Peters does not explicitly describe empathy or empathic listening as a transferable skill. (This might be because his primary focus is on the musical expression of emotion, and that is generally configured in an egological manner as a matter of what the subject would like to be the case; but this issue is beyond the scope of the present article.) In this respect, notwithstanding the actual musical examples cited, it might initially seem to be unclear whether Peters' argument pertains to music specifically, as opposed to one of the other arts (e.g. literature, about which there is much discussion of empathic "identification" with fictional characters [e.g. Kieran, 2010]), as opposed to the Arts generically (pace Kant, the curious possibility that empathy might turn out to be a means of bridging cognitive and practical reason), as opposed to other forms of expert listening (e.g. psychoanalytic listening), and as opposed to naturalistic everyday listening. Nevertheless, as the context provided above implies, much of Peters' argument seems to be applicable to these other domains with little substantive change; it is not tied to auditory experience alone or to the aesthetics of musical sound specifically. In a sense, my point here is a trivial one, given that his argument is precisely about the idea that musical empathy and social empathy feed off one another somehow, but for my money there seems to be a wider implication here. This implication is that, once empathy has been acknowledged as a key transferable skill, it should then become clear that all musical listening really does is to tap into this broader cross-domain human skill and feed the musical subject's development of more widely applicable skills. After all, at one point Peters writes that "The felt quality of sonic shapes [...] is, in part, given by our bodily knowledge of the emotional coloring of our own actions" (2015, p. 9, emphasis added), and, later on, that musical empathy "is supported by, and in turn supports, social empathy with those factually or imaginatively involved in the musical event" (p. 11, emphasis added).

This seems to be implied from Peters' discussion of the relationship between musical empathy and social empathy, which is based on the claim that the two types of empathy are "distinct, but dialectically entwined" (2015, p. 11). I am not convinced that positing a "dialectical" relationship between musical empathy and social empathy, necessary though it may be conceptually, addresses the broader pragmatic issue, for the difficulty seems to me not so much to keep the two types of empathy from merging into one another dialectically. Rather, and more to the point, the difficulty seems to me to be to prevent musical empathy from being assimilated into social empathy, the latter being broader, more fundamental and earlier to develop, the former being a subset of the latter. If, as Peters argues, we need to acknowledge that "sounding materials, cross-modal perceptions, bodily hermeneutic, and ongoing emotional narrative interrelate and intertwine" $(2015$, p. 9$)$, then we surely also need to acknowledge the assimilation of one type of empathy to, or into, the other. In any case, it is difficult to imagine a situation in which it would be desirable to keep the two types of empathy meaningfully distinct: we desire our musicking to be humanly 
meaningful, not formalistically autonomous, and this means grounding musical empathy in social empathy, not vice versa, lest we lose the anthropomorphic ascriptions upon which we rely in empathic listening. This idea is congruent with the basic premise of work such as that of Felicity Laurence (2008), which must assume that there is some kind of common ground between musical empathy and social empathy in order to make claims about the transformative power of musicking, about its ability to intervene in, ameliorate and perhaps even prevent real life conflict situations.

I am probably being a little pedantic here, of course. For Peters himself has already incorporated a space for the dialectical imbrication of the two types of empathy, where he notes $(2015$, p. 13, n. 22$)$ that Caroline Waddington's (2013) tripartite model of empathy ("shared approach," "intentional awareness," "special connection") allows for the possibility that the "special connection" between co-performers is a matter more of social empathy than of musical empathy. But I think that there is a wider point here concerning empathy's ability to maneuver itself into all sorts of domains unbeknownst to the musical listener, for empathy to thereby have an impact beyond the immediate musical engagement of subject and object - with the important consequence that the broader para- or meta-musical benefits of empathic listening may not necessarily be obvious from a simple witness to the present-on-hand act of listening itself.

\section{INDETERMINACY}

I close with a brief note on what I think is the most radical of Peter's various claims, one which he seems to leave tantalizingly hanging. Unpacking some points consequent upon the claim that the listener's musical interpretation of a work is grounded in cross-modal experience and "corpophonic knowledge" (Peters, 2015, p. 8), he gives an interesting twist to the debate between Roger Scruton and Andy Hamilton on the relative weighting that should be given to acousmatic perception within musical understanding: "since hearing the performance in the sounds is [...] not necessary for the sounds to be perceived as bodily feelings, it is also seen that the ownership of any emergent agency is, at first, indeterminate" (p. 8). Notwithstanding what seems to me to be a slight over-emphasis on the construction of a determining and controlling agency, it is surely an open question concerning the extent to which this "indeterminacy" (which elsewhere Peters describes as a "protean agency" [p. 10]) completely disappears under the weight of the virtual persona or is completely overwhelmed and overwritten by the multitude of the mature "feelings' dynamics," and the emergence of the fully formed "musical other." After all, there are numerous accounts of (non-musical) empathy that point to the importance of regulating the intensity and extent of empathy with the other for the sake of the wellbeing of both the subject and the other (e.g. Hodges \& Wegner, 1997; Myers \& Hodges, 2009). The point to be made is that, as a transferable skill, empathic listening requires, more than anything, the fundamental openness that lies at its core to remain open - and not to be closed down in some kind of hard-edged imaginative attribution of a persona (an extreme to which Peters seems to be occasionally tempted). In such a manner, what might be engaged in one particular listening experience might be able to return in (be transferred to) another quite different experience with its own quite different phenomenology (and emotional expression).

This suggests three important points of departure for further work, based on what Peters has usefully scoped out in his article. First, we need further investigation into how empathic listening emerges in musical practice (as opposed to being somehow simply "turned on" instantaneously like a light switch); indeed, how it might in fact sometimes fail to emerge - or get distracted and sidetracked from the task. Secondly, it behooves us to consider the far-reaching practical implications of how empathic listening can be taught, nurtured, and sustained in cultural activity. Thirdly, we need wide-ranging research into how, as a transferable skill, specifically musical empathic listening can be used in such a way that it might impact productively on other non-musical human activities. All of these activities are also important matters of education and pedagogy.

\section{NOTES}

[1] Correspondence can be addressed to: Dr. Anthony Gritten, Royal Academy of Music, Marylebone Road, London, NW1 5HT, UK, E-mail: a.gritten@ram.ac.uk 


\section{REFERENCES}

Aragno, A. (2008). The language of empathy: An analysis of its constitution, development and role in psychoanalytic listening. Journal of the American psychoanalytic association, 56(3), 713-740.

Baron-Cohen, S. (2011). Zero degrees of empathy: A new understanding of cruelty and kindness. London: Penguin.

Boddington, G., \& Bannerman, C. (2004). Sharing the process: A consideration of inter-authorship in the performing arts. Digital Creativity, 15(2), 76-80.

Cameron, L. (2011). Empathy: A review: Living with uncertainty working paper 1. Retrieved from http://www.open.ac.uk/researchprojects/livingwithuncertainty/sites/www.open.ac.uk.researchprojects.livin gwithuncertainty/files/pics/d1 15149.pdf [accessed 21-8-14]

Egermann, H., \& McAdams, S. (2013). Empathy and emotional contagion as a link between recognized and felt emotions in music listening. Music Perception, 31(2), 139-156.

Haney, K. (1994). Empathy and ethics. Southwest Philosophy Review, 10(1), 57-65.

Hodges, S., \& Wegner, D. (1997). Automatic and controlled empathy. In W. Ickes (Ed.), Empathic accuracy (pp. 311-339). New York: Guilford Press.

Hodges, S., \& Klein, K. (2001). Regulating the costs of empathy: The price of being human. Journal of Socio-Economics, 30, 437-452.

Kemp, A. (1996). The Musical temperament: Psychology and personality of musicians. Oxford: Oxford University Press.

Kieran, M. (2010). Emotions, art and immorality. In P. Goldie (Ed.), The Oxford handbook of philosophy of emotion (pp. 681-703). Oxford: Oxford University Press.

Krueger, J. (2013). Empathy, enaction, and shared musical experience: Evidence from infant cognition. In T. Cochrane, B. Fantini \& K. Scherer (Eds.), The Emotional power of music: Multidisciplinary perspectives on musical expression, arousal and social control (pp. 177-196). Oxford: Oxford University Press.

Laurence, F. (2008). Music and empathy. In O. Urbain (Ed.), Music and conflict transformation: Harmonies and dissonances in geopolitics (pp. 13-25). London: I. B. Tauris.

Molnar-Szakacs, I., \& Overy, K. (2006). Music and mirror neurons: From motion to 'e'motion. Social Cognitive and Affective Neuroscience, 1, 235-241.

Murdoch, I. (1970). The Sovereignty of good. London: Routledge \& Kegan Paul.

Myers, M., \& Hodges, S. (2009). Making it up and making do: Simulation, imagination, and empathic accuracy. In K. Markman, W. Klein \& J. Suhr (Eds.), Handbook of imagination and mental simulation (pp. 281-294). New York: Psychology Press.

Overy, K., \& Molnar-Szakacs, I. (2009). Being together in time: Musical experience and the mirror neuron system. Music Perception, 26(5), 489-504.

Peters, D. (2015). Musical empathy, emotional co-constitution, and the "musical other". Empirical Musicology Review, 10(1), 2-15.

Rabinowitch, T. (2012). Musical games and empathy. Education and health, 30(3), 80-84. 
Seddon, F. (2005). Modes of communication during jazz improvisation. Psychology of Music, 34, 148-165.

Skura, M. (1980). Creativity: Transgressing the limits of consciousness. Daedalus, 109, 127-146.

Smith, A. (2003). Husserl and the Cartesian meditations. London: Routledge.

Waddington, C. (2013). Co-performer empathy and peak performance in expert ensemble playing. In A. Williamon \& W. Goebl (Eds.), Proceedings of the International Symposium on Performance Science 2013 (pp. 331-336). Brussels, Belgium: European Association of Conservatoires (AEC).

Wispé, L. (1987). History of the concept of empathy. In N. Eisenberg \& J. Stayer (Eds.), Empathy and its development (pp. 17-36). Cambridge: Cambridge University Press. 